\title{
Insights into the Molecular Role of Endocannabinoids in Diabetes Mellitus
}

\author{
Aayush Sehgal $^{1}$ (D), Tapan Behl 1,* (D), Ishnoor Kaur ${ }^{1}$ (D), Sukhbir Singh ${ }^{1}$ (D), Neelam Sharma ${ }^{1}$ (D), \\ Sandeep Arora 1 (D) \\ 1 Chitkara College of Pharmacy, Chitkara University, Punjab, India \\ * Correspondence: tapanbehl31@gmail.com
}

Scopus Author ID: 56560241200

Received: 7.03.2021; Revised: 12.04.2021; Accepted: 15.04.2021; Published: 20.04.2021

\begin{abstract}
In the past few years, the pathophysiological role of various factors in type 2 diabetes mellitus has been fully explored. Subsequently, this marked the progression in the development of a novel therapeutic agent. Such brain-derived neurotropic factors, including neurotrophic factor-2 and antiinflammatory agents for the treatment of diabetes, have emerged. However, the therapeutic potential of endocannabinoids in type 2 diabetes mellitus is still not fully understood. At present, cannabinoids are under research for their therapeutic and safety profile issues in numerous thrust areas. Its wide biological actions are implemented through cannabinoid receptor type 1(CB1) and CB2 receptors, which find major applications as anti-arthritic, anti-inflammatory, neuroprotective, anti-cancer, and antidiabetic therapeutics with lesser side effects than any other traditional therapy. The current review aims to reveal detailed aspects of pathological and physiological pathways with endocannabinoids followed in disease progression. Different alterations induced by them in the pancreas, such as 2-arachidonylglycerol and anandamide during hyperglycemia, clearly verify their participation in the progression of type 2 diabetes. Activation of both cannabinoid receptors results in metabolic changes inside the body, and receptor antagonist rimonabant has been proven to be protective in controlling insulin resistance in diabetic patients. Therefore, endocannabinoids are a promising target in new drug developments and further in-depth analysis of their hidden aspects, which would help develop alternate beneficial targets in combating the progression of diabetes.
\end{abstract}

Keywords: cannabinoid receptor; diabetes mellitus; endocannabinoid system; hyperglycemia; neurotropic factor-2.

(C) 2021 by the authors. This article is an open-access article distributed under the terms and conditions of the Creative Commons Attribution (CC BY) license (https://creativecommons.org/licenses/by/4.0/).

\section{Introduction}

The endocannabinoid system (ECS) controls our body's physiological processes, maintaining energy homeostasis by controlling the mechanism of energetic balance. It comprises peripheral and central receptors, i.e., cannabinoid receptor type 1 and 2 (CB1 and CB2), endogenic and exogenic agonist for regulating degradation and synthesis of its endogenic ligands. Endocannabinoids are active factors, immunosuppressive in nature, and play a vital role in various autoimmune diseases such as diabetes, where necessary action takes place by apoptosis to prevent suppression/prevention synthesis and proliferation of cytokines chemokines and inductor regulation of $\mathrm{T}$ lymphocytes [1,2]. It regulates the homeostasis of energy, hunger and controls lipid and glucose metabolism. Experiments conducted in different preclinical research establish the influence of inactivation of the pharmacological and genetic makeup of CB1 in enhancing the energy expenditure and decreasing body weight of rodents. 
Thus, this system body's enhanced activity has evolved out as an emerging therapy for obese patients suffering from type 2 diabetes mellitus by controlling and regulating endocrine functioning $[3,4]$. In recent times, cannabinoids are of much attraction for controlling cellular functions of alpha as well as beta cells in islets of Langerhans, where presences of CB1 and CB2 cannabinoid receptors have been reported. Experimental findings reported the impact of these two receptors along with their agonists on the secretion of somatostatin, glucagon, and insulin and the regulation of pancreatic endocrine functioning. The regulation of these cells helps in maintaining glucose levels within optimum limits. Since insulin acts as a major mediator for glucose homeostasis, it controls the proliferation of beta cells in an autocrine manner $[4,5]$. A different set of studies are being conducted to define the effects of these endogenous cannabinoids on proliferation action of beta cells in which the biological actions of factors are controlled by coupling of mentioned two receptors with specific $\mathrm{G}$ protein, $\mathrm{CB} 1 \mathrm{R}$, and CB2R involved in stimulating the secretion of insulin is under investigation [6].

Endocannabinoids also affect insulin functioning in tissues that are dependent on insulin, such as muscle and liver. It exerts an immunosuppressive action via CB2 receptors and aid in the inhibition of leukocyte proliferation, decreased pro-inflammatory cytokine secretion, and induction of cell apoptosis [7]. Thus, endocannabinoids are of great interest for researchers to discover their use as immunosuppressants for numerous types of autoimmune disorders like type 2 diabetes to modulate insulin and glucagon secretion for regulating glucose homeostasis $[8,9]$. Research conducted by French and Spanish authors has presented in their work about endogenous participation of CB1R, which participates in regulating beta cells' growth and viability. It also highlights the blockade strategy for combating age-related metabolic diseases, and this can further be exploited for insulin resistance, proving to be an appropriate therapy for type 2 diabetes. The blockade or modulation of the endocannabinoid system can also reduce the chances of cardiovascular disorder in a diabetic person. Its participation in the central and peripheral energy storage and food intake promotion directly affects individuals' appetite and feeding behavior $[10,11]$. This system was developed over the past two decades. Complete understanding of the molecular entity of this system has led to the development of its agonists as well as antagonists as a boon to the clinical field. It is interesting to note that synthetic endocannabinoids exhibit many potential therapeutic roles [12], with antagonists of CB1 receptors directly affect the physiology of the liver, pancreas, and skeletal muscle. Observations suggest that use of inverse agonists of CB1 receptor such as taranabant and rimonabant can be used for managing type 2 diabetes mediated complications, including failure of $\beta$-cell causing hyperglycemia, progressive gain in weight, insulin resistance, cardiovascular risk factors such as high blood pressure, atherogenic dyslipidemia, coronary artery disease, cerebrovascular and peripheral artery diseases [13]. There is an increased need to manage weight for diabetic patients to improve glycemic control because of EC system CB1 receptors' participation in it. The current review aims to summarize all the available knowledge about endogenous cannabinoid systems and exploit their potential in the treatment of diabetes.

\section{Endocannabinoid System: An Overview}

The endogenous cannabinoid system is a multifaceted signaling system that includes endogenous ligands of cannabinoid receptors and enzymes required for the degradation and biosynthesis of endocannabinoids (ECs) [14]. This ubiquitous system that appeared during evolution exerts vital function on cells and tissues. Endocannabinoids are lipid-based signaling molecules [15], and this term was coined soon after the detection of endogenous ligands of 9- 
tetrahydrocannabinol receptors [16]. Signaling systems include enzymes involved in the degradation and synthesis of this system. The EC system developed is one of the major neuromodulatory systems present inside the brain, where it regulates inhibition of synaptic activity via its neurotransmitters [17]. ECS serves its vital role in peripheral organs, which are involved in the regulation of energy metabolism. It regulates behavior at various sites throughout the body, thus increasing the total intake of energy. 2-arachidonoyl glycerol and anandamide are the two major types of ECs, which are derived from triglycerides and membrane phospholipids [18].

In comparison to other neurotransmitters, ECs are produced in response to the acute level of stimulation through enhanced intracellular calcium concentration, which is more specifically known as use-dependent synthesis. These enzymes are specific for developing two mentioned types of ECs and are released immediately from cells when biosynthesized, possessing their capability to bind and functionalized $\mathrm{CB}$ receptors. $\mathrm{CB} 1$ and $\mathrm{CB} 2$ are identified molecular characteristics of $\mathrm{CB}$ receptors that reside exclusively in immune cells and blood [19]. Enzymatic hydrolysis and their intracellular level help in removing ECs from extracellular spaces by selective uptake into cells. Fatty acid amide hydroxylase plays a major role in the degradation of EC [20].

Monoacylglycerol lipase and pre (FAAH), i.e., fatty acid amide hydrolase, are CB2 receptors located in numerous body organs, where the former links the endocannabinoid and eicosanoid systems by facilitating degradation of endocannabinoid 2-arachidaoylglycerol to form arachidonic acid [21]. The study related to ECs is made about pharmacological and genetic methods, which revealed its broad role in various pathological and physiological processes such as motor learning, the release of neuromodulator, appetite, synaptic plasticity, fertility and reproduction, neurodegenerative diseases, energy metabolism modulation, neuroendocrine and autonomic responses, pain sensation, inhibition of cancerous cell growth, inflammation, mental disorders, induction of bradycardia, and hypotension [22,23]. The ECS is considered a unified physiological system involved in modulating nutrient intake, storage, metabolism, transport, and dysfunction related to comorbidities associated with abdominal adiposity. The over-activity of ECS can occur due to enhanced synthesis of EC and can be due to over expression of $\mathrm{CB}$ receptor or decreased degradation of EC. In contrast to this, any sort of pharmacological modulation in ECS over-activity can significantly reduce EC production on a theoretical basis. This results in enhanced degradation of endocannabinoids and blockade of CB1 receptors [24]. The ECS comprises seven-member G proteins that couples with cannabinoid receptors, mainly CB1 and CB2. A well-established study has been performed on cannabis-like substances and their derived lipid molecules such as 2-arachidonoylglycerol and anandamide. Out of the two, CB1 receptors are present most abundantly in various peripheral and central nervous systems such as the cerebral cortex, hippocampus, forebrain, cerebellum, hypothalamus, and basal ganglia. It expresses itself via astrocyte processes, axon terminals, interneurons, and neuron dendrites. CB1 is articulated in peripheral nerves of the gastrointestinal tract, pancreas, adrenal medulla, skeletal muscles, autonomic nervous system, liver, and skeletal muscles [25], and it regulates cognitive motor and sensory actions of the brain [26]. On the other hand, CB2 receptors are most commonly found in the cerebral cortex, brainstem, cerebellum, adipose tissue, circulating immune cells, thymus and spleen. In such areas, it carries out processes like modulation of cytokine release from immune cells. ECS belongs to the eicosanoid family, including $\mathrm{N}$-arachidonoyl glyceryl ether, $\mathrm{N}$ arachidonoylethanolamide, and 0 -arachidonoyl ethanolamine, $\mathrm{N}$-arachidonoyl dopamine, and 
2-arachidonylglycerol. The ligand interacts with cannabinoid receptors and helps regulate and maintain certain body functions and internal homeostasis via the expanded endocannabinoid system called endocannabinoidome [27]. ECS is present throughout the body and regulates the working and functioning of the immune system, digestive system, food intake, processing and storage of energy, stress and mood reactions, inflammatory responses, and female and male fertility [28].

EC gets released in a receptor-dependent manner from amino acids, this release occurs in order to converse the glutamatergic synapses and GABAergic signaling messengers. Released EC modulates postsynaptic transmission as well as the interaction of neurotransmitters such as dopamine [29]. The released cannabinoids are transported towards the cells via definite uptake systems and regularly degraded by enzymes such as monoacylglycerol lipase and fatty acid amide hydrolase. The term 'endocannabinoid' was coined in the 1990s, soon after the detection of delta9-tetrhydrocannabinol receptors and their ligands. Since it has an "exostatic" character in environmental conditions, the activation of the ECS system can lead to overeating and orientation of metabolism in energy storage [30,31].

Besides this, EC system is regulated through a feed-forward directing mechanism in obesity. It is also involved in pathophysiological loops which maintain aggravation related to overweight. Existing evidence suggests the role/involvement of EC system in physiological functions. Studies were also done in regards to the maintenance of stress as well as energy balance. Thus, EC is basically an assimilated physiological system that modulates transport, intake, metabolism, storage, and dysfunction related to comorbidities of abdominal adiposity and disorders like atherosclerosis [32,33].

On the contrary, modulations at pharmacological levels aim to correct the over-activity of the EC system, leading to reduced production, blockage of transportation, and enhanced degradation on a theoretical basis. Thus, the endocannabinoid system presents a major challenge in comprehending its signaling system's complication and designing drugs with selective action [34]. Additionally, it postulates an opportunity to discover new therapeutic agents. Presently, much work is done to discover unique agonists and antagonists with specific receptor selectivity, which provides a better comprehension of the physiological participation of ECS in a large number of pathologies [35]. This could further lead to advancement in the development of drugs that can modulate ECS activity and exert therapeutic potential in this regard (Figure 1).

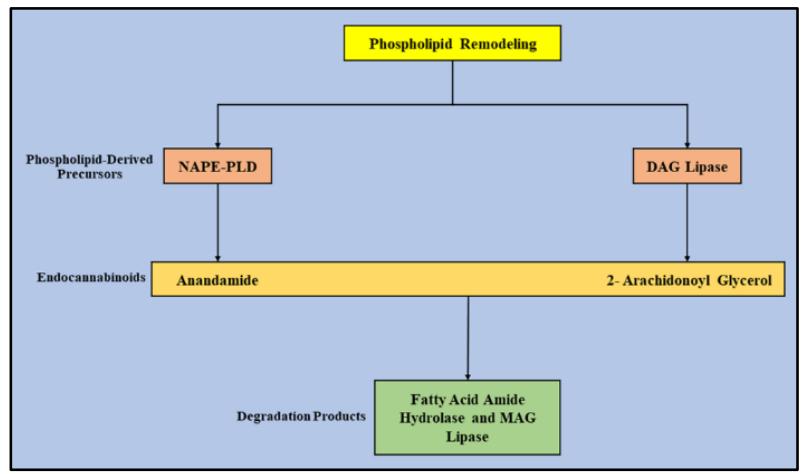

Figure 1. Enzymatic synthesis and degradation of endocannabinoids.

\section{CB1 Receptors and their Antagonism}

CB1 and CB2 receptors are seven-membered receptors coupled with G-protein receptors, similar to that of the receptors of various other neurotransmitters and hormones. The 
presence of such receptors is all over the peripheral organs of the body. These receptors are known to mediate food intake via the hypothalamus and thus control the limbic system, homeostasis of the body, and other eating aspects [36,37]. The activity of antagonists of CB1receptor such as rimonabant blocks lipogenesis in the body, which is the initial step and clears the EC system's understanding mechanism in controlling various metabolic processes in the body. These receptors are also found in the pancreas, where they regulate the pathophysiology of type 2 diabetes mellitus and promote fat accumulation, lipogenesis, insulin resistance, induction of glucose intolerance, homeostasis moderation via its expression on peripheral tissues. Pharmacological investigations related to antagonists of CB1 receptors have emphasized on detection of substances that could act as possible antagonists or agonists for cannabinoid receptors $[38,39]$. In contrast, the antagonists can adopt any possible mechanisms to show their effect on the specific receptors. The ligands may competitively antagonize the ligands and activate them by endogenously releasing endocannabinoids or by acting as an inverse agonist to modulate receptor activity by transforming it from "on," i.e., active or "off," i.e., inactive state. Inverse agonists, similar to antagonists, block binding with receptors, and activation occur with competitive agonists' help. They also oblige spontaneous internal receptor signaling, causing an effect opposite in comparison by an agonist, which is called inverse agonism [40, 41]. The inverse agonists of CB1 receptors' behavioral and physiological actions are because of their ability to obstruct basic receptor activity or blockade of EC signaling at the pharmacological level. The explanation related to the expression of CB1 receptors in adipocytes and the capability of several antagonists such as rimonabant to block lipogenesis that EC initially stimulated signifies an initial step in thorough understanding about ECS involvement in the regulation of various metabolic processes [42]. The following has also been confirmed by the blockade of cannabinoid receptors with this molecule's help, leading to increased expression of adinopectins [43].

Undeniably, rimonabant is one of most extensively investigated compound which acts as both invert agonist and antagonist for the CB1 receptor. AM4113, which has a high affinity, serves as a neutral molecule for the receptor, reduces body weight and food intake in rats in a dose-dependent manner as that of other inverse agonists consequently supports the energy balancing role of ECS $[44,45]$. It is noteworthy that these neutral agonists' actions are considerably less tricky than AM251, which is an inverse agonist for the CB1 receptor. Lastly, since these receptors are $\mathrm{G}$ protein-coupled receptors [46], it can be assumed that their action can also be influenced by the activity of basal G proteins, which could affect EC's metabolic activities. Thus, all the factors that could affect $G$ proteins' activity can be considered a possible therapeutic approach for treating the antagonism of CB1 receptor. Though, the interest and experimental data in support of this in the current time is still lacking. Among these, rimonabant which is a derivative of diarylpyrazole 141716A was the first antagonist investigated and reported for its activity on animals as well as humans in clinical trials. Rimonabant is one of the highest commercialized molecules in many countries, and its successful development boosted the search for ligands of the receptor as a unique chemical entity possessing a similar pharmacological profile as that of rimonabant [47]. Many other cannabinoid receptors targeting drugs have also been developed [48]. Any sort of substitutional modification or bioisosteric replacement of pyrazole entity present in rimonabant pharmacophore proves to be a novel approach for the generation of new ligands for CB1 receptor that acts as inverse or neutral agonists. Some of the known CB1 receptor modulators include triazole, amino alkylindole, and 
diarylpyrazole derivatives. All these have been actively perused in the pharmaceutical industry as a leading pharmacotherapy for metabolic disorders related to diabetes and obesity [49].

At the surface level, the use of such selective antagonists as lead molecules for weight management has been successfully examined on obese mouse models. The evaluation parameters included measurement of adipose tissue mass, metabolic, distribution parameters of insulin, glucose, and lipid levels in plasma. Although, very little information is known about inverse agonists other than rimonabant, on which a large amount of positive experimental data is already known [50]. The study involving brain imaging involved MK-9470 as a high affinity selected inverse CB1 antagonist for CB1 receptor, which showed higher binding in substantia nigra, hippocampus, putamen, cerebellum, globus pallidus, and cerebral cortex. In monkeys, positron emission tomography scans showed a large amount of uptake, as clearly observed through autoradiographic studies. Additionally, MK-0364 which is also one of the inverse agonists for this receptor, presented a dose-dependent reduction in binding shown through clinical trials, which included obese persons. Thus, this unbane practice presented a vital target for explaining non-invasive techniques for treating diabetic patients by using CB1 receptors $[51,52]$. This signaling pathway's mechanism involves activation of CB receptors coupled with $\mathrm{G}$ proteins and causes activation of numerous signaling pathways at the intracellular level. Along with the inhibition activity of adenylate cyclase and inhibition of protein kinase A [53], activation of $\mathrm{CB} 1$ receptor leads to stimulation of $\mathrm{K}^{+}$channels that inwardly rectifies together with inhibition of voltage-regulated $\mathrm{Ca}^{2+}$ channels, directing them to regulate synaptic transmission [54]. The activation of CB1 can also result in the instigation of phospholipase C$\gamma$ and phosphatidylinositol-3-kinase to release intracellular calcium ions [55]. Other than this, certain focal-adhesion kinases are regulated extracellularly, and mitogen-stimulated kinases are also activated by stimulation of CB receptors [56, 57].

Various endogenous ligands for the receptor, such as anandamide, were synthesized from the forerunner protein ethanolamine called $\mathrm{N}$-arachidonoyl 1-phosphatidylethanolamine (NAPE), which is formed from the action of NAPE-phospholipase upon intracellular membranes [58]. Also, NAPE is known to exert no effect on anandamide and N-acyl ethanolamines in mice's brains. Anandamide is produced by the hydrolytic breakdown of diacylglycerols containing specific diacylglycerol lipases such as 2-arachidonate on its plasma membranes. Both anandamide and 2-AG have similar binding affinities for CB1 and CB2 receptors, though they differ in their ability to activate the receptor, with anandamide presenting its activity as a partial agonist only. In comparison, 2-AG activates both cannabinoid receptors [59]. Several pieces of evidence support the diffusion of these endocannabinoids into cell membranes to activate cannabinoid receptors within the cells where they were initially produced and released to target $\mathrm{CB}$ receptors located on other cells. Within the brain, the concentration of $2 \mathrm{AG}$ is much higher, making it a better receptor ligand. The termination of EC action occurs due to cellular uptake and enzymatic hydrolysis within the cell in which FAAH, i.e., fatty acid amide hydrolase and monoacylglycerol lipase, are responsible for its serine hydrolysis [60] (Figure 2). 


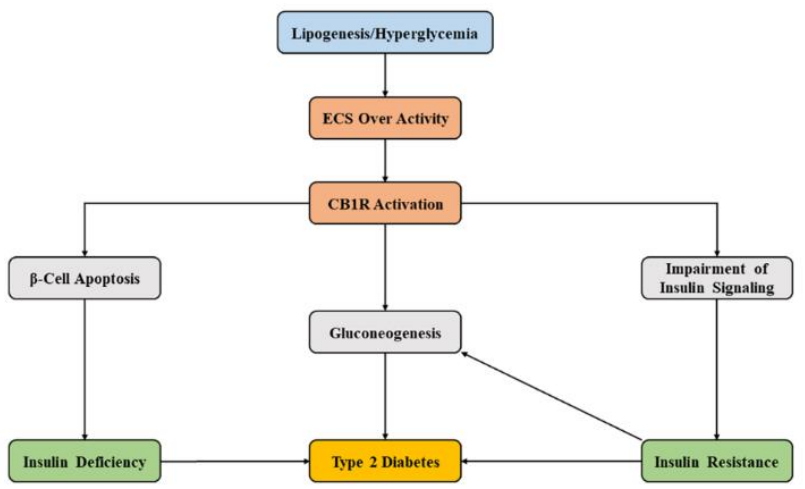

Figure 2. Role of CB1 receptor in the development of diabetes.

\section{Therapeutic Potential of Endocannabinoids}

Various clinical researches have suggested the involvement of different ailments triggered when optimal ECS functioning is disturbed [61]. In such cases, phytocannabinoids can be exploited for therapeutic action because of their lesser side effects and non-interference in the body's physiological functioning. This has been observed through different clinical trials [62]. It is well-known that CB exerts intrinsic activity via its receptors. They lack undesirable psychotropic effects and make cannabinoids one of the best bioactive entities possessing maximum therapeutic potential. The drugs acting on cannabinoid receptors can follow multiple mechanisms and act as antagonists for respective receptors, presenting anxiolytic, antidepressant, neuroprotective, and antidiabetic actions [63, 64]. The following pharmacological potential has been attributed to the allosteric modification of $\mathrm{d}$ - and $\mathrm{m}$ receptors. A large amount of therapeutic potential of EC in widespread diseases is because of its neuroprotective and immunomodulatory properties. Research data available till now also supports the anti-inflammatory potential of EC [65] since they reduce the phenotype of autoimmune inflammation and inhibit interferon-b and NF-kB [66]. It exerts beneficial action like analgesic and anti-inflammatory activity in chronic disorders such as cancer, epilepsy, and seizures [67] by acting as an antipsychotic, vasorelaxant, antiemetic, antispasmodic, antibacterial, antidiabetic, vasorelaxant, anxiolytic, antibacterial, and anti-ischemic agent. ECs also show positive results in cancer research and induce apoptosis of lungs' cancerous cells and, therefore, cause cell death by modulating mitochondrial membrane channel [68]. This illustrates success in inhibition of prostate cancer, small lung cancer, growth and invasion of breast cancer, metastasis, reduction of gliomas, hepatocellular carcinoma, and colon carcinogenesis. It down-regulates genes like ID-1, which are implicated in different types of cancers, kills cancerous cells' activity, and shields non-transformed complement from death. It also causes the prevention of neuropathic pain induced in chemotherapy and devoid of any sort of cognitive impairment, providing rewarding effects [69]. ECs, when given at a lower dose in cultured T-cells, leading to apoptosis of CD8+ and CD4+ cells by enhancing the growth of reactive oxygen species. This further upsurges natural killer T-cells' growth and induces lymphopenia by reducing T- and B- cells. Though it does not significantly affect NK cells, EC selectively boosts up innate immunity and overpowers acquired immunity [70]. In addition to this, EC reduces leucocyte recruitment, acute lung infection and lung resistance, and expression of certain molecules like TNF and IL-6, causing suppression of inflammation [71]. It was also observed that when diabetic mice were treated with ECs, the incidence of diabetes decreased from $86 \%$ to $30 \%$. ECs reduce pro-inflammatory cytokines together with increased antiinflammatory cytokines. Effective treatment with EC in arthritic mice induced due to collagen 
blocks disease progression by suppressing proliferation of lymphocytes and TNF expression, protecting against joint damage in arthritis [72,73]. One of the major side effects faced is a thickening of a synovial membrane. An injection of EC cannabinoid drugs directly into the brain preserves anxiolysis and abolishes psychotic symptoms and abolishes fearful memories [74]. Thus, it helps treat dysphoria, mental sedation, physical sedation, anxiety-related issues, and intoxication.

\section{Endocannabinoid System, Pancreas and Hyperglycaemia}

ECs system controls the body's metabolism by regulating insulin level and glucose utilization or uptake by tissue and shows its effect on glucose tolerance, as evidenced by certain studies [75]. The metabolic state or beta-cell differentiation in the body regulates the expression of $\mathrm{CB} 1$ receptor inside the pancreas. This further enhances glucose impairment by involving an indirect mechanism. Several laboratory data also show the involvement of both CB1 and CB2 receptors in maintaining the process of homeostasis and ECS level inside the body regulated by insulin and glucose concentration [76,77]. It has been detected that the pancreas of hyperglycaemic patients contains overactive ECS as well as diacylglycerol lipase alpha and NAPE-PDL. ECS exerts an effect on insulin level, metabolism, and glucose utilization, ultimately leading to hypoadiponectinemia and hyperinsulinemia. In addition, ECS also modulates the metabolism of fatty acid and glucose in the pancreas and adipose tissues [77]. CB1 leads to enhanced blood glucose levels by inhibiting insulin release and its utilization in peripheral tissues. Expression of both $\mathrm{CB} 1$ and $\mathrm{CB} 2$ receptors and biosynthesis of EC occurs in islets of Langerhans inside pancreatic B-cells, and these receptors tend to modulate the islet actions [78]. The administration of AEA at laboratory levels results in glucose intolerance, mainly due to reduced glucose-dependent secretion of insulin [79]. Thus, stimulation of CB1 and $\mathrm{CB} 2$ receptors improves glucose handling in the body since these are present inside the pancreas and possibly involve modulation of calcium oscillations that affect insulin secretion [80]. The islets of Langerhans express both receptors along with machinery involved in the modulation of glucose concentration in the body [81]. Immunofluorescence studies have revealed that the actual location of $\mathrm{CB} 1$ receptor is A-cells which are involved in glucagon secretion, while that of CB2 receptors is D-cells which secretes somatostatin and enhances insulin secretion in humans.

Numerous researchers speculated the involvement of ECs in the pathogenesis of diabetes mellitus. A large number of pathophysiological alterations take place in hyperglycemia, leading to dysfunction. Various pathways involved act via inhibiting fatty acid amide hydrolase1 that catabolizes anandamide [82]. It also induces protein kinase $\mathrm{C} /$ diacylglycerol pathway to activate phospholipase $\mathrm{D}$, simultaneously increasing phosphatidic acid production later on forms 2-AG. Studies conducted showed the involvement of EC system under enhanced glucose concentration. This clearly established a link between both of them [83]. Another study showed the participation of anandamide in regulation and the metabolism of energy balance [84]. It was shown that stimulation, differentiation of fibroblast occurs in the adipocytes by activating downstream signaling of PPAR $\gamma$, i.e., peroxisome proliferatoractivated receptor- $\gamma$. Furthermore, this induces glucose uptake followed by insulin uptake inside adipocytes [85]. Though the molecular mechanism behind the mentioned function is independent of PPAR- $\gamma$, anandamide is believed to be the possible reason behind the activation of CB1 receptor. Subsequently, activation of the signaling pathway occurs, involved in the upregulation/expression of nitric oxide synthase. Nitric oxide significantly modulates lipolysis 
and leads to the induction of signaling receptors that are probably persuaded due to anandamide [86]. This can lead to increased glucose uptake within adipocytes (Figure 3).

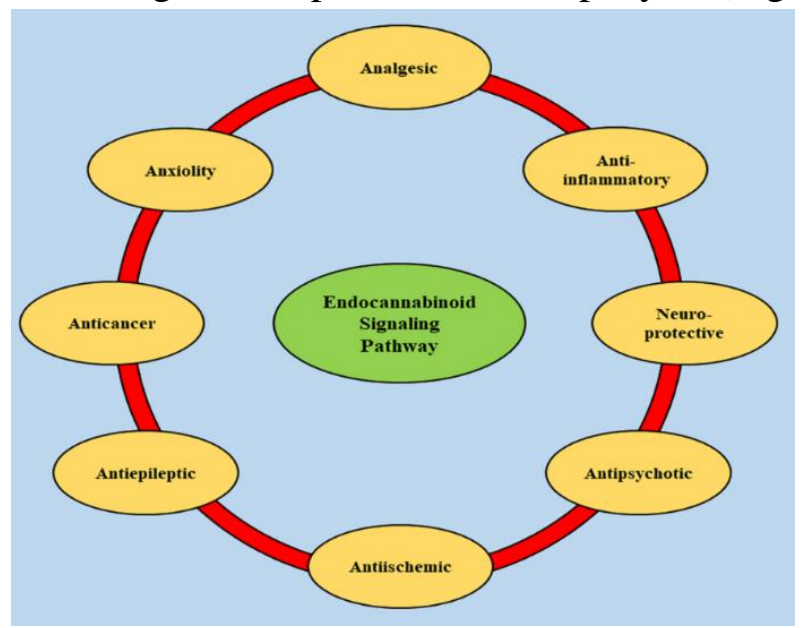

Figure 3. Pharmacological action of the cannabinoid system.

\section{Role of Endocannabinoid System in Management of Diabetes Mellitus}

Diabetes is caused due to hyperglycemia and is characterized by insulin resistance or absence of insulin. It is mainly due to the autoimmune demolition of islet cells. Obesity is the primary reason behind insulin resistance, leading to type 2 diabetes mellitus [86]. ECs amplifies food intake in obese patients by involving both central as well as peripheral CB1 receptors. This can result in adipogenesis, hepatic steatosis, insulin resistance, and lipogenesis. Blockade of receptors using suitable drugs like rimonabant shows improvement in metabolic issues like enhanced level of triglycerides and cholesterol in the body. Though the presence, functions, and action of ECS in pancreatic cells are under wide investigation, the expression of CB1 and CB2 receptors inside islet cells are highly contradictory in nature and show a strong dependence on species $[87,88]$. The primary receptors are present in rats, but that of the latter is debatable. Enzymes are responsible for synthesizing and metabolizing, which occurs within the cells of the human pancreas. The presence of CB1 receptors in the pancreas is controversial and is implicated in the secretion of insulin. These receptors are believed to enhance the proliferation of cells from a therapeutic point [89]. The clinical trials define a clear picture of the involvement of cannabinoid receptors in diabetic complications. RIO Diabetes was the first clinical trial conducted to determine the safety and efficacy of CB1 antagonists in obese diabetic patients. The same was controlled using sulfonylureas and thus improved metabolic profile, body weight, cholesterol level, blood pressure, and glycaemic control. The vital function of ECS in the pathogenesis of type 2 diabetes mellitus was reinforced by elevated levels of cannabinoid in disease [90,91].

At present, substantial interest is shifting towards the implication of certain synthetic ligands for cannabinoids in the modulation of different immune responses, including subsequent production of cytokine and activation of T-lymphocytes. It is also known to weaken the harshness of autoimmune responses in diabetic disorders, thus reducing the number of lymphocytic cells, interleukins, interferons, and tumor necrosis factors [92,93]. The treatment aims to protect and preserve insulin content in the pancreas, which further lowers glucose levels in treated groups. It also showed eminent immunosuppressive capability, whose psychoactive effects limit them for therapeutic purposes. Various studies have shown the involvement of cannabinoids in reducing insulitis, which causes a reduction in pro-inflammatory cytokines and 
patients suffering from type 2 diabetes mellitus [94]. Altogether, it can be concluded that ECS is known to play a crucial role in controlling the development of diabetes [95]. The exact mechanism and cellular targets lying behind them are not yet fully comprehended. Therefore, there is a need to investigate the functioning of cannabinoid receptors in regulating the working of islet cells and developing suitable antagonists of CB1 receptors that can be further exploited in different clinical trials [96]. The cannabinoids that are suitably derived from plants, such as cannabidiol, do not report any psychoactive or toxic effects to humans. Such products serve as the latest promising avenues to treat diabetic complications and shields pancreatic beta cells from any oxidative injuries [97].

\section{Conclusion and Future Perspectives}

Though there is much debate in the arena of research regarding ECs, numerous clinical trials and experiments performed evidently demonstrate vital participation of ECS and inhibition effects of cannabinoid receptors in the development of the diabetic disorder. The recently performed preclinical studies aimed to develop a therapeutic strategy of CB1 antagonists to encounter adverse effects that occur during the disease. As already discussed in the present review, the inhibition of these receptors can attenuate reactive oxygen species and inflammatory responses to target different tissues and cell types in diabetic complications $[98,99]$. The agonists for CB2 receptors exert useful outcomes in diabetes by attenuating oxidative stress. The naturally existing cannabinoids have incredible therapeutic potential antiinflammatory and antioxidant properties that can be put into human use. Thus, in the upcoming time, it will be highly interesting to investigate both agonist and antagonistic activities of natural cannabinoids on respective receptors in diabetic patients [100]. Hopefully, these novel approaches will be of great use in the near future for clinical practice related to diabetes. Currently, metabolic disorders related to diabetes are highest in the United States, where receptor blockers like rimonabant showed positive results in obese patients facing insulin resistance, causing type 2 diabetes mellitus, overall reducing the risk of dyslipidemia, cardiovascular diseases, hyperglycemia, and inflammation [101]. The discovery of the endocannabinoid system is a hallmark for neuroscience, metabolic research, and the exploitation of various pathophysiological functions. This serves as a promising target of numerous therapeutic applications by blocking cannabinoid receptors [102]. Certain modifications in lifestyle and the effect of rimonabant should be considered in diabetic patients. The safety issues are related to some of the digestive side effects, mood disorder, and depression in persons with rimonabant therapy. However, it can prove an essential novel approach for managing diabetes and other agents that lower glucose levels in the body [103]. Further clinical research is required to support unique strategies exerting long-term safety and efficacy in patients with type 2 diabetes mellitus. Similarly, further information about the benefit-risk profile of antagonists of cannabinoid receptors is required to deal with other metabolic disorders [104]. Evidence from preclinical studies conducted authorizes the use of ECS in cancer treatment, arthritis, diabetes, and ischemia. Cannabinoids serve as a promising element for discovering new drugs, having a wide action spectrum in various medical conditions with rare side effects. Nevertheless, more studies are needed to exploit the potential actions of cannabinoids in humans. Therefore, it is expected that modern developments in the field of physiological, pharmaceutical, and pharmacological sciences would lead to the development of new therapeutic strategies with the least side effects in metabolic diabetic disorder [105]. 


\section{Funding}

This review received no external funding.

\section{Acknowledgments}

The authors express gratitude to Chitkara College of Pharmacy, Chitkara University, Punjab, India, for motivational support for this review's compilation.

\section{Conflict of Interest}

The authors declare no conflict of interest.

\section{References}

1. Rodriguez de Fonseca, F.; Del, A.I.; Bermudez-Silva, F.J.; Bilbao, A.; Cippitelli, A.; Navarro, M. The endocannabinoid system: physiology and pharmacology. Alcohol Alcohol. 2005, 40, 2-14. https://doi.org/10.1093/alcalc/agh110.

2. Cota, D.; Tschöp, M.H.; Horvath, T.L.; Levine, A.S. Cannabinoids, opioids and eating behavior: the molecular face of hedonism? Brain Res. Rev. 2006, 51, 85-107. https://doi.org/10.1016/j.brainresrev.2005.10.004.

3. Mendizabal, V.E.; Adler, G.E. Cannabinoids as therapeutic agents in cardiovascular disease: a tale of passions and illusions. Br. J. Pharmacol. 2007, 151, 427-440. https://dx.doi.org/10.1038\%2Fsj.bjp.0707261.

4. Xie, S.; Furjanic, M.A.; Ferrara, J.J.; McAndrew, N.R.; Ardino, E.L.; Ngondara, A.; Bernstein, Y.; Thomas, K.J.; Kim, E.; Walker, J.M.; Nagar, S.; Ward, S.J.; Raffa, R.B. The endocannabinoid system and rimonabant: a new drug with a novel mechanism of action involving cannabinoid CB1 receptor antagonism-or inverse agonism-as potential obesity treatment and other therapeutic use. J. Clin. Pharm. Ther. 2007, 32, 209-231. https://doi.org/10.1111/j.1365-2710.2007.00817.x.

5. Lee, N.J.; Herzog, H. Coordinated regulation of energy and glucose homeostasis by insulin and the NPY system. J. Neuroendocrinol. 2020, 2, 12925. https://doi.org/10.1111/jne.12925.

6. Campos, A.C.; Moreira, F.A.; Gomes, F.V.; Del Bel, E.A.; Guimarães, F.S. Multiple mechanisms involved in the large-spectrum therapeutic potential of cannabidiol in psychiatric disorders. Philos. Trans. R Soc. Lond. B Biol. Sci. 2012, 367, 3364-3378. https://dx.doi.org/10.1098\%2Frstb.2011.0389.

7. Kaur, I.; Behl, T.; Bungau, S.; Zengin, G.; Kumar, A.; El-Esawi, M.A.; Khullar, G.; Venkatachalam, T.; Arora, S. The endocannabinoid signaling pathway as an emerging target in pharmacotherapy, earmarking mitigation of destructive events in rheumatoid arthritis. Life Sci. 2020, 257, 118109. https://doi.org/10.1016/j.lfs.2020.118109.

8. Devinsky, O.; Cilio, M.R.; Cross, H.; Fernandez-Ruiz, J.; French, J.; Hill, C. Cannabidiol: pharmacology and potential therapeutic role in epilepsy and other neuropsychiatric disorders. Epilepsia 2014, 55, 791-802. https://doi.org/10.1111/epi.12631.

9. Sartim, A.G.; Guimarães, F.S.; Joca, S.R. Antidepressantlike effect of cannabidiol injection into the ventral medial prefrontal cortex-Possible involvement of 5-HT1A and CB1 receptors. Behav. Brain Res. 2016, 303, 218-227. https://doi.org/10.1016/j.bbr.2016.01.033.

10. Harris, H.M.; Sufka, K.J.; Gul, W.; ElSohly, M.A. Effects of delta-9-tetrahydrocannabinol and cannabidiol on cisplatin-induced neuropathy in mice. Planta Med. 2016, 82, 1169-1172. https://doi.org/10.1055/s-0042106303.

11. Robson, P.J. Therapeutic potential of cannabinoid medicines. Drug Test Anal. 2014, 6, $24-30$. https://doi.org/10.1002/dta.1529.

12. Sholler, D.J.; Huestis, M.A.; Amendolara, B.; Vandrey, R.; Cooper, Z.D. Therapeutic potential and safety considerations for the clinical use of synthetic cannabinoids. Pharmacol. Biochem. Behav. 2020, 199, 173059. https://doi.org/10.1016/j.pbb.2020.173059.

13. Russo, E.B.; Hohmann, A.G. Role of cannabinoids in pain management. In: Deer TR, Leong MS, Buvanendran A, Gordin V, Kim PS, Panchal SJ, Ray AL, editors. Comprehensive treatment of chronic pain by medical, interventional, and integrative approaches 2013. New York: Springer, 2013, 181-197. https://doi.org/10.1007/978-1-4614-1560-2_18. 
14. Sara, J.W. Physiology of the endogenous cannabinoid system: basic science for the clinician. J. Am. Acad. Child Psy. 2020, 59, S126-S127. https://doi.org/10.1016/j.jaac.2020.07.492.

15. Ellermann, M.; Pacheco, A.R.; Jimenez, A.G.; Russell, R.M.; Cuesta, S. Endocannabinoids Inhibit the Induction of Virulence in Enteric Pathogens. Cell 2020, 183, 650-665. https://doi.org/10.1016/j.cell.2020.09.022.

16. Jung, K.M.; Piomelli, D. The endocannabinoid system. Ref. Module Life Sci. 2020. https://doi.org/10.1016/B978-0-12-809633-8.21365-4.

17. Lu, H.C.; Mackie, K. Review of the Endocannabinoid System. Biol. Psychiatry Cogn. Neurosci. Neuroimaging 2020, https://doi.org/10.1016/j.bpsc.2020.07.016.

18. Miller, S.; Daily, L.; Dharla, V.; Gertsch, J.; Malamas, M.S.; Ojima, I.; Kaczocha, M.; Ogasawara, D.; Straiker, A. Endocannabinoid metabolism and transport as targets to regulate intraocular pressure. Exp. Eye Res. 2020, 201,108266. https://doi.org/10.1016/j.exer.2020.108266.

19. Sharma, D.S.; Paddibhatla, I.; Raghuwanshi, S.; Malleswarapu, M.; Sangeeth, A.; Kovuru, N.; Dahariya, S.; Gautum, D.K.; Pallepati, A.; Gutti, R.K. Endocannabinoid system: Role in blood cell development, neuroimmune interactions and associated disorders. J. Neuroimmunol. 2021, 577501. https://doi.org/10.1016/j.jneuroim.2021.577501.

20. Murataeva, N.; Daily, L.; Taylor, X.; Dhopeshwarkar, A.; Hu, S.S.J.; Miller, S.; McHugh, D.; Oehler, O.; Li, S.; Bonanno, J.A.; Mackie, K.; Straiker, A. Evidence for a GPR18 role in chemotaxis, proliferation, and the course of wound closure in cornea. Cornea 2019, 38, 90. https://doi.org/10.1097/ico.0000000000001934.

21. Deng, H.; Li, W. Monoacylglycerol lipase inhibitors: modulators for lipid metabolism in cancer malignancy, neurological and metabolic disorders. Acta Pharm. Sin. B 2020, $10, \quad 582-602$. https://doi.org/10.1016/j.apsb.2019.10.006.

22. Pagano, E.; Orlando, P.; Finizio, S.; Rossi, A.; Buono, L.; Iannotti, F.A.; Piscitelli, F.; Izzo, A.A.; Di Marzo, V.; Borrelli, F. Role of the endocannabinoid system in the control of mouse myometrium contractility during the menstrual cycle. Biochem. Pharmacol. 2017, 124, 83-93. https://doi.org/10.1016/j.bcp.2016.11.023.

23. Sachs, J.; McGlade, E.; Yurgelun-Todd, D. Safety and toxicology of cannabinoids. Neurother. 2015, 12, 735746. https://doi.org/10.1007/s13311-015-0380-8.

24. Ujváry, I.; Hanuš, L. Human metabolites of cannabidiol: a review on their formation, biological activity, and relevance in therapy. Cannabis Cannabinoid Res. 2016, 1, 90-101. https://dx.doi.org/10.1089\%2Fcan.2015.0012.

25. Erdozain, A.M.; Rubio, M.; Meana, J.J.; Fernández-Ruiz, J.; Callado, L.F. Altered CB1 receptor coupling to G-proteins in the post-mortem caudate nucleus and cerebellum of alcoholic subjects. J. Psychopharmacol. 2015, 29, 1137-1145. https://doi.org/10.1177/0269881115599388.

26. Jansmaa, J.; Brinkmana, F.; Hemertb, S.; Aidy, S.E. Targeting the endocannabinoid system with microbial interventions to improve gut integrity. Prog. Neuro-Psychopharmacol. Biol. Psy. 2021, 106, 110169. https://doi.org/10.1016/j.pnpbp.2020.110169.

27. Cristino, L.; Bisogno, T.; Di Marzo, V. Cannabinoids and the expanded endocannabinoid system in neurological disorders. Nat. Rev. Neurol. 2020, 16, 9-29. https://doi.org/10.1038/s41582-019-0284-z.

28. Ryberg, E.; Larsson, N.; Sjögren, S.; Hjorth, S.; Hermansson, N.O.; Leonova, J.; Elebring, T.; Nilsson, K.; Drmota, T.; Greasley, P.J. The orphan receptor GPR55 is a novel cannabinoid receptor. Br. J. Pharmacol. 2007, 152, 1092-1101. https://doi.org/10.1038/sj.bjp.0707460.

29. Hirono, M.; Yanagawa, Y. Endocannabinoids regulate cerebellar GABAergic transmission in a synapse typedependent manner. J. Neurosci. Res. 2021, 99, 898-913. https://doi.org/10.1002/jnr.24765.

30. Resstel, L.; Tavares, R.F.; Lisboa, S.F.; Joca, S.R.; Correa, F.; Guimarães, F.S. 5-HT1A receptors are involved in the cannabidiol-induced attenuation of behavioural and cardiovascular responses to acute restraint stress in rats. Br. J. Pharmacol. 2009, 156, 181-188. https://dx.doi.org/10.1111\%2Fj.14765381.2008.00046.x.

31. Argueta, D.A.; DiPatrizio, N.V. Peripheral endocannabinoid signaling controls hyperphagia in western dietinduced obesity. Physiol. Behav. 2017, 171, 32-39. https://doi.org/10.1016/j.physbeh.2016.12.044.

32. Foster, D.A. Phosphatidic acid and lipidsensing by mTOR. Trends Endocrino. Meta. 2013, 24, $272-278$. https://doi.org/10.1016/j.tem.2013.02.003.

33. Guillamat-Prats, R.; Rami, M.; Herzig, S.; Steffens, S. Endocannabinoid Signalling in Atherosclerosis and Related Metabolic Complications. Thromb. Haemost. 2019, 119, 567-575. https://doi.org/10.1055/s-00391678738 . 
34. Morales, P.; Jagerovic, N. Novel approaches and current challenges with targeting the endocannabinoid system. Expert Opin. Drug Discov. 2020, 15, 917-930. https://doi.org/10.1080/17460441.2020.1752178.

35. Pacher, P.; Bátkai, S.; Kunos, G. The endocannabinoid system as an emerging target of pharmacotherapy. Pharmacol. Rev. 2006, 58, 389-462. https://doi.org/10.1124/pr.58.3.2.

36. Ramírez-Orozco, R.E.; García-Ruiz, R.; Morales, P.; Villalón, C.M.; Villafán-Bernal, J.R.; MarichalCancino, B.A. Potential metabolic and behavioural roles of the putative endocannabinoid receptors GPR18, GPR55 and GPR119 in feeding. Curr. Neuropharmacol. 2019, 17, 947-960. https://doi.org/10.2174/1570159x17666190118143014.

37. Sappington, R.M.; Sidorova, T.; Long, D.J.; Calkins, D.J. TRPV1: contribution to retinal ganglion cell apoptosis and increased intracellular Ca2+ with exposure to hydrostatic pressure. Inv. Oph. Vis. Sci. 2009, 50, 717-728. https://doi.org/10.1167/iovs.08-2321.

38. Rajesh, M.; Mukhopadhyay, P.; Batkai, S.; Patel, V.; Saito, K.; Matsumoto, S.; Kashiwaya, Y.; Horváth, B.; Mukhopadhyay, B.; Becker, L.; Haskó, G. Cannabidiol attenuates cardiac dysfunction, oxidative stress, fibrosis, and inflammatory and cell death signaling pathways in diabetic cardiomyopathy. J. Am. Coll. Cardiol. 2010, 56, 2115-2125. https://doi.org/10.1016/j.jacc.2010.07.033.

39. Amato, G.; Khan, N.S.; Maitra, R. A patent update on cannabinoid receptor 1 antagonists (2015-2018). Expert Opin. Ther. Pat. 2019, 29, 261-269. https://doi.org/10.1080/13543776.2019.1597851.

40. Booz, G.W. Cannabidiol as an emergent therapeutic strategy for lessening the impact of inflammation on oxidative stress. Free Radic. Biol. Med. 2011, 51, 1054-1061. https://doi.org/10.1016/j.freeradbiomed.2011.01.007.

41. Abidi, A.H.; Alghamdi, S.S.; Dabbous, M.K.; Tipton, D.A.; Mustafa, S.M.; Moore, B.M. Cannabinoid type2 receptor agonist, inverse agonist, and anandamide regulation of inflammatory responses in IL-1 $\beta$ stimulated primary human periodontal ligament fibroblasts. J. Periodontal Res. 2020, 55, 762-783. https://doi.org/10.1111/jre.12765.

42. Bazwinsky-Wutschke, I.; Zipprich, A.; Dehghani, F. Endocannabinoid System in Hepatic Glucose Metabolism, Fatty Liver Disease, and Cirrhosis. Int. J. Mol. Sci. 2019, 20, 2516. https://doi.org/10.3390/ijms20102516.

43. Mechoulam, R.; Peters, M.; Murillo-Rodriguez, E.; Hanuš, L.O. Cannabidiol-recent advances. Chem. Biodiv. 2007, 4, 1678-1692. https://doi.org/10.1002/cbdv.200790147.

44. Hollander, P.A.; Amod, A.; Litwak, L.E.; Chaudhari, U. Effect of rimonabanton glycemic control in insulintreated type 2 diabetes: the ARPEGGIO trial. Diabetes Care 2010, 33, 605-607. https://doi.org/10.2337/dc090455 .

45. Eid, B.G.; Neamatallah, T.; Hanafy, A.; El-Bassossy, H.M.; Aldawsari, H.M.; Vemuri, K.; Makriyannis, A. Effects of the CB1 Receptor Antagonists AM6545 and AM4113 on Insulin Resistance in a High-Fructose High-Salt Rat Model of Metabolic Syndrome. Medicina (Kaunas) 2020, 56, 573. https://doi.org/10.3390/medicina56110573.

46. Tham, M.; Yilmaz, O.; Alaverdashvili, M.; Kelly, M.E.M.; Denovan-Wright, E.M.; Laprairie, R.B. Allosteric and orthosteric pharmacology of cannabidiol and cannabidiol-dimethylheptyl at the type 1 and type 2 cannabinoid receptors. Br. J. Pharmacol. 2019, 176, 1455-1469. https://doi.org/10.1111/bph.14440.

47. Tiyerili, V.; Zimmer, S.; Jung, S.; Wassmann, K.; Naehle, C.P.; Lutjohann, D. CB1 receptor inhibition leads to decreased vascular AT1 receptor expression, inhibition of oxidative stress and improved endothelial function. Basic Res. Cardiol. 2010, 105, 465-477. https://doi.org/10.1007/s00395-010-0090-7.

48. Murphy, T.; Le Foll, B. Targeting the endocannabinoid CB1 receptor to treat body weight disorders: a preclinical and clinical review of the therapeutic potential of past and present CB1 drugs. Biomolecules 2020, 10, 855. https://doi.org/10.3390/biom10060855.

49. Wang, Y.; Rimm, E.B.; Stampfer, M.J.; Willett, W.C.; Hu, F.B. Comparison of abdominal adiposity and overall obesity in predicting risk of type 2 diabetes among men. Am. J. Clin. Nutr. 2005, 81, 555-563. https://doi.org/10.1093/ajcn/81.3.555.

50. Mohammed, N.; Ceprian, M.; Jimenez, L.; Ruth Pazos, M.; Martínez-Orgado, J. Neuroprotective effects of cannabidiol in hypoxic ischemic insult. The therapeutic window in newborn mice. CNS Neuro. Dis. Drug Targets 2017, 16, 102-108. https://doi.org/10.2174/1871527315666160927110305.

51. Lafuente, H.; Pazos, M.R.; Alvarez, A.; Mohammed, N.; Santos, M.; Arizti, M.; Alvarez, F.J.; MartinezOrgado, J.A. Effects of cannabidiol and hypothermia on shortterm brain damage in new-born piglets after acute hypoxia-ischemia. Front. Neurosci. 2016, 10, 323. https://doi.org/10.3389/fnins.2016.00323. 
52. Silvestri, C.; Paris, D.; Martella, A.; Melck, D.; Guadagnino, I.; Cawthorne, M. Two non-psychoactive cannabinoids reduce intracellular lipid levels and inhibit hepatosteatosis. J. Hepatol. 2015, 62, 1382-1390. https://doi.org/10.1016/j.jhep.2015.01.001.

53. Ye, L.; Cao, Z.; Wang, W.; Zhou, N. New Insights in Cannabinoid Receptor Structure and Signaling. Curr. Mol. Pharmacol. 2019, 12, 239-248. https://doi.org/10.2174/1874467212666190215112036.

54. Zanelati, T.V.; Biojone, C.; Moreira, F.A.; Guimaraes, F.S.; Joca, S.R. Antidepressant-like effects of cannabidiol in mice: possible involvement of 5-HT1A receptors. Br. J. Pharmacol. 2010, 159, 122-128. https://doi.org/10.1111/j.1476-5381.2009.00521.x.

55. Hegyi, Z.; Oláh, T.; Kőszeghy, Á.; Piscitelli, F.; Holló, K.; Pál, B.; Csernoch, L.; Di Marzo, V.; Antal, M. $\mathrm{CB} 1$ receptor activation induces intracellular $\mathrm{Ca} 2+$ mobilization and 2-arachidonoylglycerol release in rodent spinal cord astrocytes. Sci. Rep. 2018, 8, 10562. https://doi.org/10.1038/s41598-018-28763-6.

56. Reddy, D.S.; Golub, V.M. The pharmacological basis of cannabis therapy for epilepsy. J. Pharmacol. Exp. Ther. 2016, 357, 45-55. https://doi.org/10.1124/jpet.115.230151.

57. Dalton, G.D.; Carney, S.T.; Marshburn, J.D.; Norford, D.C.; Howlett, A.C. CB1 Cannabinoid Receptors Stimulate G $\beta \gamma$-GRK2-Mediated FAK Phosphorylation at Tyrosine 925 to Regulate ERK Activation Involving Neuronal Focal Adhesions. Front. Cell Neurosci. 2020, 14, 176. https://doi.org/10.3389/fncel.2020.00176.

58. Laprairie, R.B.; Bagher, A.M.; Kelly, M.E.; Denovan Wright, E.M. Cannabidiol is a negative allosteric modulator of the cannabinoid CB1 receptor. Br. J. Pharmacol. 2015, 172, 4790-4805. https://doi.org/10.1111/bph.13250.

59. Ivy D, Palese F, Vozella V, Fotio Y, Yalcin A, Ramirez G, Mears D, Wynn G, Piomelli D. Cannabinoid CB2 receptors mediate the anxiolytic-like effects of monoacylglycerol lipase inhibition in a rat model of predatorinduced fear. Neuropsychopharmacol. 2020, 45, 1330-1338. https://doi.org/10.1038/s41386-020-0696-x.

60. Biernacki, M.; Skrzydlewska, E. Metabolism of endocannabinoids. Postepy. Hig. Med. Dosw. 2016, 70, 830843. https://doi.org/10.5604/17322693.1213898.

61. Argenziano, M.; Tortora, C.; Bellini, G.; Di Paola, A.; Punzo, F.; Rossi, F. The Endocannabinoid System in Pediatric Inflammatory and Immune Diseases. Int. J. Mol. Sci. 2019, 20, 5875. https://doi.org/10.3390/ijms20235875.

62. Jones, N.A.; Glyn, S.E.; Akiyama, S.; Hill, T.D.; Hill, A.J.; Weston, S.E.; Burnett, M.D.; Yamasaki, Y.; Stephens, G.J.; Whalley, B.J.; Williams, C.M. Cannabidiol exerts anticonvulsant effects in animal models of temporal lobe and partial seizures. Seizure 2012, 21, 344-352. https://doi.org/10.1016/j.seizure.2012.03.001.

63. Navarro, G.; Morales, P.; Rodríguez-Cueto, C.; Fernández-Ruiz, J.; Jagerovic, N.; Franco, R. Targeting cannabinoid CB2 receptors in the central nervous system. medicinal chemistry approaches with focus on neurodegenerative disorders. Front. Neurosci. 2016, 10, 406. https://doi.org/10.3389/fnins.2016.00406.

64. Páez, J.A.; Campillo, N.E. Innovative therapeutic potential of cannabinoid receptors as targets in alzheimer's disease and less well-known diseases. Curr. Med. Chem. 2019, 26, 3300-3340. https://doi.org/10.2174/0929867325666180226095132.

65. Joffre, J.; Yeh, C.C.; Wong, E.; Thete, M.; Xu, F.; Zlatanova, I.; Lloyd, E.; Kobzik, L.; Legrand, M.; Hellman, J. Activation of CB1R promotes lipopolysaccharide-induced IL-10 secretion by monocytic myeloid-derived suppressive cells and reduces acute inflammation and organ injury. J. Immunol. 2020, 204, 3339-3350. https://doi.org/10.4049/jimmunol.2000213.

66. Zuardi, A.W.; Crippa, J.A.; Hallak, J.E.; Moreira, F.A.; Guimaraes, F.S. Cannabidiol, a Cannabis sativa constituent, as an antipsychotic drug. Braz. J. Med. Biol. Res. 2006, 39, 421-429. https://doi.org/10.1590/s0100-879x2006000400001.

67. Raucci, U.; Pietrafusa, N.; Paolino, M.C.; Di Nardo, G.; Villa, M.P.; Pavone, P.; Terrin, G.; Specchio, N.; Striano, P.; Parisi, P. Cannabidiol treatment for refractory epilepsies in pediatrics. Front. Pharmacol. 2020, 11, 586110. https://doi.org/10.3389/fphar.2020.586110.

68. Tomko, A.M.; Whynot, E.G.; Ellis, L.D.; Dupré, D.J. Anti-cancer potential of cannabinoids, terpenes, and flavonoids present in cannabis. Cancers 2020, 12, 1985. https://doi.org/10.3390/cancers12071985.

69. Oshitari, T.; Fujimoto, N.; Hanawa, K.; Adachi-Usami, E.; Roy, S Effect of chronic hyperglycemia on intraocular pressure in patients with diabetes. Am. J. 2007, 143, 363-365. https://doi.org/10.1016/j.ajo.2006.09.033.

70. Masuzawa, K.; Jesmin, S.; Maeda, S.; Kaji, Y.; Oshika, T.; Zaedi, S. A model of retinal ischemia-reperfusion injury in rats by subconjunctival injection of endothelin-1. Exp. Biol. Med. (Maywood) 2006, 23, 1085-1089. https://pubmed.ncbi.nlm.nih.gov/16741054/. 
71. Ali, A.M.; El-Tawil, O.S.; Al-Mokaddem, A.K.; Abd El-Rahman, S.S. Promoted inhibition of TLR4/miR155/ NFkB p65 signaling by cannabinoid receptor 2 agonist (AM1241), aborts inflammation and progress of hepatic fibrosis induced by thioacetamide. Chem. Biol. Interact 2021, 336, 09398. https://doi.org/10.1016/j.cbi.2021.109398.

72. Alhouayek, M.; Muccioli, G.G. COX-2-derived endocannabinoid metabolites as novel inflammatory mediators. Trends Pharmacol. Sci. 2014, 35, 284-292. https://doi.org/10.1016/j.tips.2014.03.001.

73. Rojas, A.; Dingledine, R. Ionotropic glutamate receptors: regulation by G-protein-coupled receptors. Mol. Pharmacol. 2013, 83, 746-752. https://doi.org/10.1124/mol.112.083352.

74. Harr, M.W.; Distelhorst, C.W. Apoptosis and autophagy: decoding calcium signals that mediate life or death. Cold Spring Harb. Biol. 2010, 2, 5579. https://doi.org/10.1101/cshperspect.a005579.

75. Gillies, R.; Lee, K.; Vanin, S.; Laviolette, S.R.; Holloway, A.C.; Arany, E.; Hardy, D.B. Maternal exposure to $\Delta$ 9-tetrahydrocannabinol impairs female offspring glucose homeostasis and endocrine pancreatic development in the rat. Reprod. Toxicol. 2020, 94, 84-91. https://doi.org/10.1016/j.reprotox.2020.04.070.

76. Ruz-Maldonado, I.; Liu, B.; Atanes, P.; Pingitore, A.; Huang, G.C.; Choudhary, P.; Persaud, S.J. The cannabinoid ligands SR141716A and AM251 enhance human and mouse islet function via GPR55independent signalling. Cell Mol. Life Sci. 2020, 77, 4709-4723. https://doi.org/10.1007/s00018-019-034336.

77. Horváth, B.; Mukhopadhyay, P.; Haskó, G.; Pacher, P. The endocannabinoid system andplant-derived cannabinoids in diabetes and diabetic complications. Am. J. Pathol. 2012, 180, 432-442. https://doi.org/10.1016/j.ajpath.2011.11.003.

78. Zheng, L.; Du, Y.; Miller, C.; Gubitosi-Klug, R.A.; Ball, S.; Berkowitz, B.A. Critical role of inducible nitric oxide synthase in degeneration of retinal capillaries in mice with streptozotocin-induced diabetes. Diabetologia 2007, 50, 1987-1996. https://doi.org/10.1007/s00125-007-0734-9.

79. Kushnareva, Y.; Murphy, A.N.; Andreyev, A. Complex I-mediated reactive oxygen species generation: modulation by cytochrome $\mathrm{c}$ and $\mathrm{NAD}(\mathrm{P})+$ oxidation-reduction state. Biochem. J. 2002, 368, 545-553. https://doi.org/10.1042/bj20021121.

80. Laguerre, A.; Keutler, K.; Hauke, S.; Schultz, C. Regulation of calcium oscillations in $\beta$-Cells by co-activated cannabinoid receptors. Cell Chem. Biol. 2021, 28, 88-96. https://doi.org/10.1016/j.chembiol.2020.10.006.

81. Santoro, A.; Pisanti, S.; Grimaldi, C. Rimonabant inhibits human colon cancer cell growth and reduces the formation of precancerous lesions in the mouse colon. Int. J. Cancer 2009, 125, 996-1003. https://doi.org/10.1002/ijc.24483.

82. Di Marzo, V. The endocannabinoid system in obesity and type 2 diabetes. Diabetologia 2008, 51, 1356-1367. https://doi.org/10.1007/s00125-008-1048-2

83. Matias, I.; Gonthier, M.P.; Orlando, P.; Martiadis, V.; De Petrocellis, L.; Cervino, C.; Petrosino, S.; Hoareau, L.; Festy, F.; Pasquali, R.; Roche, R. Regulation, function, and dysregulation of endocannabinoids in models of adipose and beta-pancreatic cells and in obesity and hyperglycemia. J. Clin. Endo. Meta. 2006, 91, 31713180. https://doi.org/10.1210/jc.2005-2679.

84. Drummen, M.; Tischmann, L.; Gatta-Cherifi, B.; Cota, D.; Matias, I.; Raben, A.; Adam, T.; WesterterpPlantenga, M. Role of endocannabinoids in energy-balance regulation in participants in the postobese state-a preview study. J. Clin. Endocrinol. Metab. 2020, 105, 2511-2520. https://doi.org/10.1210/clinem/dgaa193.

85. Nucci, C.; Gasperi, V.; Tartaglione, R.; Cerulli, A.; Terrinoni, A.; Bari, M.; De Simone, C.; Agro, A.F.; Morrone, L.A.; Corasaniti, M.T.; Bagetta, G. Involvement of the endocannabinoid system in retinal damage after high intraocular pressure-induced ischemia in rats. Inv. Ophth. Vis. Sci. 2007, 48, 2997-3004. https://doi.org/10.1167/iovs.06-1355.

86. Kojta, I.; Chacińska, M.; Błachnio-Zabielska, A. Obesity, Bioactive Lipids, and Adipose Tissue Inflammation in Insulin Resistance. Nutrients 2020, 12, 1305. https://doi.org/10.3390/nu12051305.

87. Rohrbach, K.; Thomas, M.A.; Glick, S.; Fung, E.N.; Wang, V.; Watson, L.; Gregory, P.; Antel, J.; Pelleymounter, M.A. Ibipinabant attenuates beta-cell loss in male zucker diabetic fatty rats independently of its effects on body weight. Diabetes Obes. Meta. 2012, 14, 555-564. https://doi.org/10.1111/j.14631326.2012.01563.x.

88. Campos, A.C.; Brant, F.; Miranda, A.S.; Machado, F.S.; Teixeira, A.L. Cannabidiol increases survival and promotes rescue of cognitive function in a murine model of cerebral malaria. Neurosci. 2015, 289, 166-180. https://doi.org/10.1016/j.neuroscience.2014.12.051.

89. Osei-Hyiaman, D.; Liu, J.; Zhou, L.; Godlewski, G.; Harvey-White, J.; Jeong, W.I.; Bátkai, S.; Marsicano, G.; Lutz, B.; Buettner, C.; Kunos, G. Hepatic cb1 receptor is required for development of diet-induced 
steatosis, dyslipidemia, and insulin and leptin resistance in mice. J. Clin. Inv. 2008, 118, 3160-3169. https://doi.org/10.1172/jci34827.

90. Kathmann, M.; Flau, K.; Redmer, A.; Tränkle, C.; Schlicker, E. Cannabidiol is an allosteric modulator at muand delta-opioid receptors. Naunyn Schmiedebergs Arch. Pharmacol. 2006, 372, 354-361. https://link.springer.com/article/10.1007/s00210-006-0033-x.

91. Izzo, A.A.; Borrelli, F.; Capasso, R.; Di Marzo, V.; Mechoulam, R. Non-psychotropic plant cannabinoids: new therapeutic opportunities from an ancient herb. Trends Pharmacol. Sci. 2009, 30, 515-527. https://doi.org/10.1016/j.tips.2009.07.006.

92. Kim, D.K.; Ryu, D.; Koh, M.; Lee, M.W.; Lim, D.; Kim, M. Orphan nuclear receptor estrogen-related receptor gamma (errgamma) is key regulator of hepatic gluconeogenesis. J. Bio. Chem. 2012, 287, 2162821639. https://doi.org/10.1074/jbc.M111.315168.

93. Kim, D.K.; Kim, J.R.; Koh, M.; Kim, Y.D.; Lee, J.M.; Chanda, D.; Park, S.B.; Min, J.J.; Lee, C.H.; Park, T.S. Estrogen-related receptor gamma (errgamma) is a novel transcriptional regulator of phosphatidic acid phosphatase, lipin1, and inhibits hepatic insulin signaling. J. Bio. Chem. 2011, 286, 38035-38042. https://doi.org/10.1074/jbc.M111.250613.

94. Grundy, S.M. Drug therapy of the metabolic syndrome: minimizing the emerging crisis in polypharmacy. Nat. Rev. Drug Dis. 2006, 5, 295-309. https://doi.org/10.1038/nrd2005.

95. Hashiesh, H.M.; Meeran, M.F.N.; Sharma, C.; Sadek, B.; Kaabi, J.A.; Ojha, S.K. Therapeutic Potential of $\beta$ Caryophyllene: A Dietary Cannabinoid in Diabetes and Associated Complications. Nutrients 2020, 12, 2963. https://doi.org/10.3390/nu12102963.

96. Kim, W.; Doyle, M.E.; Liu, Z.; Lao, Q.; Shin, Y.K.; Carlson, O.D.; Kim, H.S.; Thomas, S.; Napora, J.K.; Lee, E.K. Cannabinoids inhibit insulin receptor signaling in pancreatic beta-cells. Diabetes 2011, 60, 11981209. https://doi.org/10.2337/db10-1550.

97. Malenczyk, K.; Jazurek, M.; Keimpema, E.; Silvestri, C.; Janikiewicz, J.; Mackie, K. CB1 cannabinoid receptors couple to focal adhesion kinase to control insulin release. J. Biol. Chem. 2013, 288, 32685-32699. https://doi.org/10.1074/jbc.M113.478354.

98. Matias, I.; Gonthier, M.P.; Orlando, P.; Martiadis, V.; De Petrocellis, L.; Cervino, C. Regulation, function, and dysregulation of endocannabinoids in models of adipose and beta-pancreatic cells and in obesity and hyperglycemia. J. Clin. Endocrinol. Meta. 2006, 91, 3171-3180. https://doi.org/10.1210/jc.2005-2679.

99. Selvarajah, D.; Gandhi, R.; Emery, C.J.; Tesfaye, S. Randomized placebo-controlled double-blind clinical trial of cannabis-based medicinal product (Sativex) in painful diabetic neuropathy: depression is a major confounding factor. Diabetes Care 2010, 33, 128-130. https://doi.org/10.2337/dc09-1029.

100.Toth, C.C.; Jedrzejewski, N.M.; Ellis, C.L.; Frey, W.H. Cannabinoid mediated modulation of neuropathic pain and microglial accumulation in a model of murine type I diabetic peripheral neuropathic pain. Mol. Pain 2010, 6, 16. https://doi.org/10.1186\%2F1744-8069-6-16.

101.Lee, C.Y.; Wey, S.P.; Liao, M.H.; Hsu, W.L.; Wu, H.Y.; Jan, T.R. A comparative study on cannabidiolinduced apoptosis in murine thymocytes and EL-4 thymoma cells. Int. Immunopharma. 2008, 8, 732-740. https://doi.org/10.1016/j.intimp.2008.01.018.

102.Patil, A.S.; Mahajan, U.B.; Agrawal, Y.O.; Patil, K.R.; Patil, C.R.; Ojha, S.; Sharma, C.; Goyal, S.N. Plantderived natural therapeutics targeting cannabinoid receptors in metabolic syndrome and its complications: A review. Biomed. Pharmacother. 2020, 132, 110889. https://doi.org/10.1016/j.biopha.2020.110889.

103.Lefranc, F.; Facchini, V.; Kiss, R. Proautophagic drugs: a novel means to combat apoptosis-resistant cancers, with a special emphasis on glioblastomas. Oncol. 2007, 12, 1395-1403. https://doi.org/10.1634/theoncologist.12-12-1395.

104.Sartim, A.G.; Guimarães, F.S.; Joca, S.R. Antidepressant-like effect of cannabidiol injection into the ventral medial prefrontal cortex-possible involvement of 5-HT1A and CB1 receptors. Behav. Brain Res. 2016, 303, 218-227. https://doi.org/10.1016/j.bbr.2016.01.033.

105.Weiss, L.; Zeira, M.; Reich, S.; Har-Noy, M.; Mechoulam, R.; Slavin, S.; Gallily, R. Cannabidiol lowers incidence of diabetes in non-obese diabetic mice. Auto-immune 2006, 39, 143-151. https://doi.org/10.1080/08916930500356674. 